\title{
Increasing the effectiveness of knowledge transfer activities and training of the forestry workforce with marteloscopes
}

\author{
by Michel Soucy ${ }^{1, *}$, Hector Guy Adégbidi ${ }^{1}$, Raffaele Spinelli and Martin Béland ${ }^{1}$
}

\begin{abstract}
Sample plots of various sizes and forms are put in place to describe and monitor trees, stands or forest characteristics. The intent is usually to provide the basis for measuring and understanding the forest. Marteloscopes, by contrast, are large plots designed for tree marking simulations, set up with human beings as the main focus: they are used for knowledge transfer activities, training of various categories of forestry workers, and even for the study of human tree selection behaviors. This distinctive type of permanent plot is relatively new and unfamiliar to North Americass forestry professionals. In this paper, we provide a working definition of marteloscopes and demonstrate how they can significantly improve knowledge exchange and learning experiences, notably for complex decisions on partial cutting treatments. Potential uses of marteloscopes, their benefits as well as some of the challenges they bring are discussed in the presentation of selected examples from Canada, the United States and Italy. These examples cover uses by research agencies, universities and nonprofit organizations. Finally, we discuss ongoing developments for marteloscopes, the standardization of protocols and the potential benefits of linking marteloscopes into an international network, as more of them are put in place in diverse and unique forest settings.
\end{abstract}

Keywords: permanent plots; tree marking; human behavior; tree classification; tree selection; selection harvest; partial harvest; selection cutting

\section{RÉSUMÉ}

En général, on établit des parcelles échantillons de tailles et de formes différentes pour décrire et suivre les caractéristiques des arbres, des peuplements et des forêts. L'objectif est habituellement de fournir les éléments de base pour mesurer et comprendre la forêt. Les martelodromes, par contre, consistent en de grandes parcelles conçues pour des exercices de marquage d'arbre orientées sur le volet humain de l'exercice : ils servent aux activités de transfert technologique, de formation de diverses catégories de travailleurs forestiers et même pour étudier comment les humains font la sélection des arbres. Ce type particulier de parcelles permanentes est relativement nouveau et peu connu des forestiers professionnels en Amérique du Nord. Cet article donne une définition pratique des martelodromes et illustre comment ils peuvent réellement améliorer léchange des connaissances et les expériences d’apprentissage, notamment pour les décisions complexes liées aux coupes partielles. Au moyen d'exemples provenant du Canada, des États-Unis et de l'Italie, l'article fait le tour des applications potentielles des martellodromes ainsi que des avantages et des défis qui s'y rattachent. Ces exemples illustrent des applications dans le domaine de la recherche, mais aussi pour les universités et les organisations sans but lucratif. Finalement, nous analysons des progrès en cours avec les martelodromes, la standardisation des protocoles et les avantages qu'il y aurait à intégrer les martelodromes en un réseau international, à mesure qu'il sen établira de nouveaux dans des environnements forestiers différents et uniques.

Mots clés : parcelles permanentes, marquage des arbres, comportement humain, classification des arbres, sélection des arbres, coupe partielle, coupe de jardinage

${ }^{1}$ École de foresterie, Université de Moncton. 165 boulevard Hébert, Edmundston, N.B. Canada, E3V2S8; ${ }^{\star}$ corresponding author: michel.soucy@umoncton.ca

${ }^{2}$ CNR IVALSA, Via Madonna del Piano 10, Sesto Fiorentino (FI), Italy 


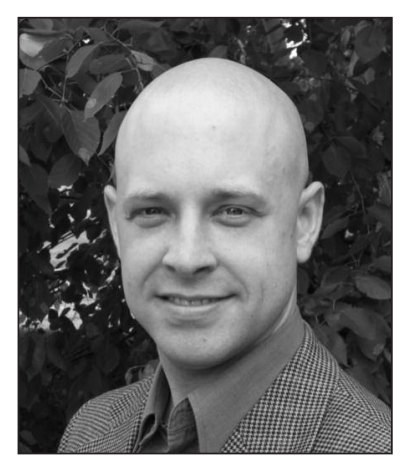

Michel Soucy

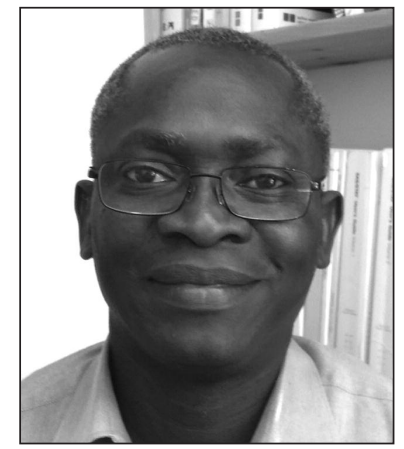

Hector Guy Adégbidi

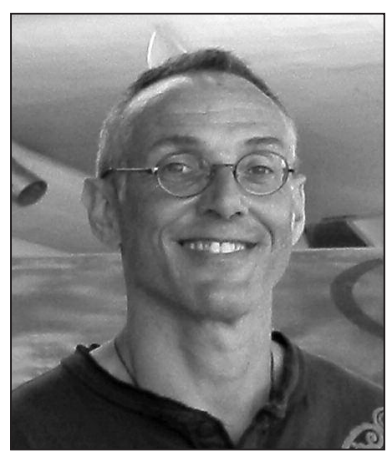

Raffaele Spinelli

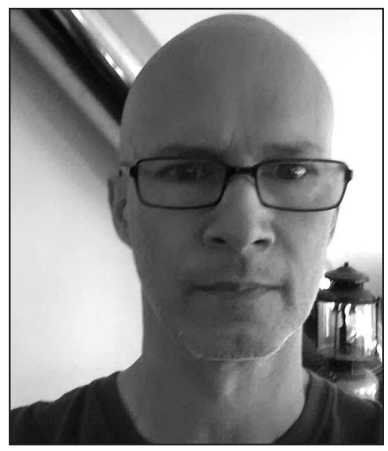

Martin Béland

\section{Introduction}

The basic training of many forestry professionals starts with some dendrology and forest mensuration courses, then follows, to various degrees, concepts of biology and ecology to build-up the knowledge necessary to effectively design forest inventories, silvicultural prescriptions and management plans that can steer stands of trees towards specific goals, given the complexities of the ecosystem. The ability to properly describe the state of the forest and to monitor its evolution has been, and still is, receiving much attention. Perfect and complete information on the whole forested area being impractical and unrealistic, sample plots in conjunction with data acquisition tools are commonly used to describe and monitor tree, stand and forest characteristics, making up the basis for informed forest management. Thus, forestry professionals are trained to set up plots and to properly identify important characteristics within those plots.

In recent times, adverse public reaction to management by clear-cut and the increasing popularity of Continuous Cover Forestry management (Pommerening and Murphy 2004, Pukkala and von Gadow 2012,) and of silvicultural systems whereby the forest canopy is maintained at one or more levels without clear felling (Franklin et al. 1997, Ruel et al. 2007, Raymond et al. 2009) make the different variants of partial cutting preferred practices in many circumstances. Thus, much effort and attention are put towards ensuring that standards are set and applied to describe, measure and classify trees. Nonetheless, it is increasingly recognized that it is very difficult and unlikely to have all forestry professionals agree on which trees to harvest when applying a partial cut. This holds true even when they have a common description of the characteristics of the trees that surround them and pursue the same outcome (Spinelli et al. 2016, Vítková et al. 2016). Tree selection happens to be one of the most complex tasks in forestry. Selecting a tree for removal not only determines the outcome of the current harvest, but also greatly influences future harvests through its effects on regeneration, available growing space, vigour, and composition of the residual stand. Usually, forestry professionals can agree on the present state and characteristics of a forest stand, the desired future state and goals for that stand, and the harvest prescription to manage the stand to reach the given goals, but they often disagree about the actual trees to select when trying to apply that prescription. This can present challenges between those who select trees and those who verify the quality of work performed. This also raises concerns of coherence between what

actually occurs and what is modelled in long-term plans. Because wood supply is increasingly becoming constrained in quantity and quality, making the right decisions when selecting trees is crucial.

Research suggests that this difficulty in agreeing on tree selection is just as significant between professional foresters as between loggers (Spinelli et al. 2016). On the other hand, expertise (experience and training) in selecting trees according to a given set of rules in a certain type of forest seems to be a driver of consistency in outcomes (Vítková et al. 2016). Practice in eastern Canada suggests that experienced loggers and harvester operators, selecting trees as part of their job, can do just as good a job as certified tree markers in their context (Girard 2008a, 2008b). Hence, if increased agreement is sought-after, it appears that tree selection requires a different, more adapted, training than that of being able to properly characterize trees and project their evolution in relation with the desired outcome.

Such observations, added to the high cost of tree marking prior to selective cutting (Cimon-Morin et al. 2010), have resulted in many jurisdictions questioning the actual benefits of tree marking. Many regions, from Europe to North America, are seriously considering different approaches to increasing the tree selection skills of their workforce, and considering transferring that responsibility to loggers and harvest machines operators. Increasing focus is thus being put on properly training the loggers and harvest machines operators. In parallel, new control mechanisms are developed and tested to ensure the quality of the tree selection work performed as per the objectives of the landowner.

Experimental forests, dedicated to both research and training, are commonly found throughout the world. Most forestry schools and training facilities have dedicated training forests but the infrastructure is mostly built and used to demonstrate how the forest ecosystem works (focus on the forest rather than on the humans...). Training plots are integral parts of those training forests. However, the purpose of the majority of those plots seems to be dedicated to characterizing and monitoring trees, stands or forest characteristics, or to learning how to properly assess and monitor those characteristics. Very few are designed or dedicated to train for tree selection skills and professional proficiency.

While concepts of proper selective cuttings have been promoted for centuries, it is only in recent decades, notably with the increasing popularity of continuous cover forestry promoted by groups such as Pro Silva (Pro Silva 2012) in Europe 
and increasingly in North America, that permanent plots dedicated specifically to training for tree selection while simultaneously integrating biodiversity aspects (Schuck et al. 2016) have started to appear in significant numbers. These permanent plots are increasingly being referred to as "marteloscopes", but this term remains mostly unknown to the forestry community, especially outside of Europe. Unfortunately, no official definition of marteloscopes could be found in the scientific literature and it is not a word commonly found in forestry dictionaries or textbooks. A basic search for the term "marteloscope" in some of the major academic database (i.e., AGRICOLA; IngentaConnect; CAB Direct; JSTOR; ScienceDirect) did not return any positive results. However, in the web pages and non-peer reviewed literature consulted, a certain consensus on its meaning seems evident. The term marteloscope is most often defined as " ... 1-hectare large, rectangular forest site where all trees are numbered, mapped and recorded. In combination with a software tool, they are used for silvicultural training" (Schuck et al. 2016). Variants in size and shape of marteloscopes are common, and the software tool often offers the ability to simulate future conditions in addition to provide a synthesis of the immediate outcome of virtual tree selection exercises. Limited information can be found on characteristics deemed important for plots dedicated to tree selection training and no official standards for installing such plots could be found. Nonetheless, the protocols used by various organisations that installed marteloscopes is usually well documented (Ammann and Junod 2012, Soucy 2014, Integrate+ 2015).

The goal of this paper is to provide a working definition of marteloscopes in the scientific literature as being permanent plots whose main focus are humans: for knowledge transfer activities, the training of various categories of forestry workers, and even the study of human tree selection behaviors. We demonstrate with examples and argue how marteloscopes can significantly improve knowledge exchange and learning experiences. The potential uses of marteloscopes, their benefits as well as some of the challenges they bring are discussed in the presentation of selected examples of marteloscopes from different regions of Europe and North America. Finally, we discuss ongoing developments for marteloscopes, the standardization of protocols and the potential benefits of linking marteloscopes into an international network as more of them are put in place in diverse and unique forest conditions.

\section{Marteloscope: More than a Permanent Plot}

A marteloscope is commonly presented as an area of forest where all the trees are mapped, numbered, measured and classified for various values such as monetary, quantity and quality of wood, aesthetics, cultural and historical attributes, vigor, wildlife, ecological and biodiversity attributes. At first glance, the various presentations of marteloscopes found seemed to direct the term to the physical plot itself. However, because marteloscopes are presented with a clear focus on human tree selection behavior, all descriptions also presented some "apparatus" (i.e., a software) specifically adapted to the plot to summarize and visualize the effects of the virtual tree selection on stand characteristics. The European Forest Institute through their Integrate+ project produced a series of booklets that illustrates well some of the possibilities of such tools (Schuck et al. 2016). Some of those software applications also assess and analyse certain human behavior characteristics such as the level of agreement between participants and summary of reasons expressed for protecting or for cutting trees (Lussier and Fontaine 2013, P. Junod, forest engineer, Centre de compétence en silviculture, Lyss, Switzerland; pers. comm., May 2014). From these observations, we suggest that the term marteloscope refer to the combination of a permanent plot (i.e., forest area) with a means to summarize and visualize the outcomes of a virtual tree selection within that plot.

From experience conducting various activities related to tree selection, a few characteristics seem important for a permanent plot to be adapted for tree selection training. Most notably, the area covered by the plot should be sufficient for a realistic (from the point of view of participants) tree marking exercise. One element that seems to raise questions for participants is in determining how to deal with the effect of out-ofplot trees on the decision to select within plot trees that are near the edge. Thus, the area should be large enough to limit that effect. It should also be large enough to allow participants to reach a level of familiarity with the forest conditions and with the selection prescription. A few marteloscopes in Canada have been set up with an extra 0.2 hectare section dedicated for familiarization of participants with the concept, the requested prescription and with the forms they have to fill. This "training" portion of the marteloscope allows participants to raise questions on their understanding of the protocol, and allows trainers to validate that participants understood well the exercise. Marteloscopes currently in place vary in size from 0.3 ha to 2.5 ha, with the most common being 1 ha (Soucy 2014, CCS 2016, Integrate+ 2016).

In terms of stand types (composition, structure, age) where marteloscopes are installed, there are no "wrong" types, but for obvious reasons, existing marteloscopes are concentrated in uneven-aged stands destined for continuous cover management and in even-aged stands that are being considered for selective thinning. The driver for selecting a possible site should be the training objectives and the silviculture questions or problems to be tackled (Amman and Junod 2012).

The tree and stand data that needs to be available from each plot depends on the tree selection prescriptions that will be used and on the criteria needed to assess the participants. The data should allow analysis of the intensity and nature of the tree selection made by each participant. Typically, tree species and diameter are common to all. Other measures such as expected product recovery, tree vigor, habitat characteristics are also common, but usually highly dependent on the mission (timber production, multifunctional forestry or conservation) of the organization that installed the marteloscope. The focus of the data and models used are most often related to growth and yield of wood, but examples can be found of marteloscopes focusing on other forest values such as ecological functions (Pro Silva France 2003) wildlife habitat and biodiversity (Schuck et al. 2016) or used to introduce concepts such as fire management and protection from falling rocks (Gineste 2010). Hence, data on plants and components of the ecosystem other than the trees give the opportunity to simulate and accurately project the effects of different tree management approaches or scenarios on the whole ecosystem. 
When marteloscopes are to be used to analyse tree selection behavior, data from participants are also required. Typically, information of each participant's profession, training and level of experience are gathered. In addition to providing the list of trees selected, participants are also commonly asked to report on the reasons that motivated their choices (such as tree health, competition, regeneration, economics). Reasons for selecting trees to be protected can be just as informative as reasons for selection trees to be harvested (Pro Silva France 1995).

The software associated with the plots commonly allows visualizing tree maps and summarizing various stand characteristics. It will permit the analysis, in near real-time, of the performance of each tree selection participant. Typically, as each participant's selection is entered into the application, with or without indication of reasons why it was selected, a summary of results and comparisons to other participants' selections can be visualized. But most importantly, many of the software developed are linked to tree and stand growth models, allowing immediate simulation and presentation of how the residual stand is expected to respond following the harvest of the selected trees, without having to wait for decades of actual growth response. This allows participants to challenge their beliefs against the current state of knowledge within a short period of time, and provides a unique opportunity for participants to assess, discuss and adapt their approaches and techniques.

In essence, marteloscopes have the following characteristics rendering them suited for human tree selection behavior analysis:

1. Defined area sufficiently large to allow for a representative tree marking exercise;

a. Represents the extent of stand conditions with its natural diversity

b. Allows participants to learn how to use the marteloscope

c. Allows participants to understand the prescription that is requested

d. Allows participants to get used to filling the required forms

e. Contains a number of trees large enough to permit participants to repeat the exercise, without fear that they remember every tree and prior decisions that they made

2. Complete information on every pertinent variable on every tree;

3. Forms or interface to capture data on participants and their tree selections;

a. List of trees selected for removal

b. Optionally:

- List of trees to be protected

- Reasons for removal or protection

- Profession; level of training; level of experience of participants

4. Interactive platform to summarize and analyse outcomes of virtual tree selections;

a. Current conditions

b. Immediate outcomes of tree selection (removals and residuals)

c. Optionally, future outcomes
Readers should be aware that other kinds of training sites exist that do not fit the definition of a marteloscope. A good example would be "martelodromes" common in the province of Québec where a number of trees are measured and classified for the purpose of training and certifying tree markers (MFFPQ 2016). Contrary to marteloscopes, these training sites do not cover a defined area and not all trees are measured, hence a constraint to per hectare calculations and whole stand summaries. It is rather a group of trees used to ensure that workers can recognize defects, harvest priority, acceptable growing stock, hazard trees, wildlife trees and classify trees appropriately, but not usable to train for the complete process of tree selection. It is important to recognize that in selection cuttings, the decision to harvest or not a given tree is related to its surrounding trees (Arbogast 1957, OMNR 2004, Bruciamacchi et al. 2005).

\section{Origins and Proliferation of Marteloscopes}

While we could not find an official origin of the term "marteloscope", the word is likely of French origin combining "martelage" (i.e., the act of selecting and marking a tree) and "scope" (i.e., an apparatus for visualising something). Permanent plots referred to as "marteloscopes" seem to have started to appear in many European countries in the 1990s and early 2000s. Marteloscopes can now be found in many European countries such as France (Génot 2009), the United Kingdom (Poore 2011), Belgium (Baar and Collard 2007), Italy (Spinelli et al. 2016), Switzerland (CCS 2016), and Germany (Integrate+2016). Pommerening et al. (2015) attributes the origins of marteloscopes in Germany to the unexpected product of a research project led by Professor Klaus von Gadow that investigated the tree selection behavior of forest managers and machine operators. The potential of the research site for teaching and training was recognized and the term "marteloscope" was subsequently attributed to brand this type of research plot to which a tree selection analysis tool is attached. Since then, this type of plot has gained in popularity and has recently begun to appear in North America. Such plots are found under various names and appellations, ranging from "permanent plots", "training plots", "tree marking training plots", "martelodromes", to variants of the word "marteloscope" ("martelloscope", "martéloscope", "M-scopes"). It is only recently that the term has started to appear in peerreviewed scientific literature (e.g., Bruciamacchie et al. 2005, Burrus and Mourey 2011, Spinelli et al. 2016, Vítková et al. 2016).

The origin of marteloscopes is obscure. They may have been already in use in Europe before the first mentions made by scientific authors in the 1990s. It is certain that the agency for the development of agriculture and forestry (ERSAF) in Lombardy (northern Italy) installed three marteloscopes before 2000, and it has been using these marteloscopes for training purposes since then. In fact, over the years the number of regional marteloscopes has increased to seven, in order to cover a range of silvicultural cases. Region Lombardy has integrated their marteloscopes into a life-long training project named "Forestry Education" with the purpose of extending forestry knowledge to other parties than just the Regional staff. Targeted stakeholders include certified forestry consultants, students and landowners. On the same line, the Forestry Service of Bolzano Province (north-eastern Italy) began 
installing their marteloscopes in 2005 using a standardized protocol developed in conjunction with the University of Vienna. To date, the number of provincial marteloscopes has grown to 18, and they are used mainly for training Provincial staff, although some events are opened to other stakeholders (Maistrelli 2014). The rapidly increasing popularity of European marteloscopes is directly related to changes in current silvicultural practices, aimed at integrating additional new goals to the conventional ones of soil protection and wood production. Promoting biodiversity is probably the strongest motivation for using marteloscopes because special training is necessary for the correct application of the new silvicultural guidelines. For this reason, marteloscopes played a prominent role in the PProSpot project, completed in 2013 (Life+ PProSpoT 2014). This project was funded by the European Union within the scope of the LIFE programme (http:// ec.europa.eu/environment/life/), and had the goal of supporting new silvicultural practices aimed at preserving sporadic species. To this purpose, three new marteloscopes were established in the hardwood forests of Central Italy, where they are still being used for training (Torregiani et al. 2012). The correct application of silvicultural guidelines aimed at increasing biodiversity is also the goal of an even larger European project, known as Integrate+ (http://www.integrateplus.org). The project is coordinated by the European Forestry Institute (EFI) with the financial support of the German Ministry for Food and Agriculture (BMEL), and represents the first attempt at integrating a wide network of 29 marteloscopes across nine countries. Following this example, eight vocational schools from Belgium, Finland, France, Italy and Spain joined into a new initiative appropriately called "hammerproject" (http://www.hammer-project.eu). The project is funded by the European Union within the scope of the ERASMUS program (http://www.erasmusprogramme.com/) and is specifically designed to support the common educational needs of the Union. Project partners have established their respective marteloscopes according to common guidelines, and they use these marteloscopes for training their students on an exchange basis with grants supporting the participation of 96 students among participating schools. In essence, the relevance of marteloscopes in Europe has grown very rapidly and the trend is towards cross-country integration, which may soon lead to standardization. These same trends are now showing within the ProSilva network, which is making increasing use of marteloscopes in its activities. Another example of the proliferation of marteloscopes is the steadily growing network of marteloscopes maintained by the Centre de compétence en silviculture in Switzerland that has reached 28 sites in 2016 (CCS 2016)

The Pro Silva network has supporters in North America that "imported" the idea of using marteloscopes to improve training and knowledge transfer on continuous cover forestry concepts. Marteloscopes started to appear around 2010 in the New England states (USA), either associated with universities or with a forestry foundation. Similarly, seven marteloscopes were installed in New-Brunswick by the University of Moncton's forestry school between 2012 and 2015. These independent initiatives raise an opportunity to link them, possibly leading to intercontinental networking and standardization.

From our search for the term marteloscope, we have identified close to 100 reported marteloscopes in Europe and
North America. Each marteloscope required extensive resources to put in place (both the physical plot and the complementary software). It is surprising that the term has yet to become more common in the scientific literature.

\section{Marteloscopes to Increase Training Effectiveness}

Unless a systematic harvest is performed, the act of selecting trees to harvest requires a complex decision-making process that is not yet well understood, resulting in discrepancies between expectations from the designer of a partial harvest prescription and the actual harvested stems (Brassard et al. 2003, Meadow and Skojac 2008). Such discrepancies and inconsistencies between the intent and outcome of a partial harvest clearly indicate that the training of the forestry workforce for tree selection is less than perfect and, at best, average.

Effectiveness of training or knowledge transfer activities can be summarized as the level of success in transmitting intended knowledge and competency to the participants. To do so, it is important that training activities permit different interactions and allow participants to validate how they perform relative to their perception and relative to the goal of the exercise. Validating one's own perception with reality is not trivial. Marteloscopes offer this possibility. Pommerening et al. (2015) give an example of a worker who was confident of having marked trees according to a crown thinning prescription while results indicated otherwise, to the surprise of the worker. Similarly, during a tree marking exercise in the Gounamitz marteloscope in Canada where over 100 participants tested their tree marking skills, some of the long-time lead developers of a tree classification system for vigor tried to mark trees to increase the average vigor of the residual stand while respecting operational constraints imposed (width and location of extraction trails to be put in, expected type and size of harvesting equipment). They were dismayed when results indicated that their actual selections were causing a degradation of average vigor. Not believing the results generated by the marteloscope software, they returned into the plot only to realize that they had failed to reach prescribed objectives because of numerous field constraints that "forced" them into willingly selecting some of the most vigorous trees and leaving behind less than ideal ones. Perception is often far from the reality but without any confrontation there is little to force one's perception to evolve. Likewise, being the one making the tree selection gives a totally different perspective to that of an outside critic that analyses punctually the acceptability of selection decisions made by someone else.

In the same line of thought, it can be just as useful to allow the comparison of individual participants to the rest of a group. Allowing trainers to see how participants behave contributes to engaging in constructive discussions and suggesting corrective actions to improve participants' competencies.

Tree selection is a multi-stage process that, in many cases includes: i) the identification of attributes such as defects (mechanical, pathological...); ii) the assessment of the effects of the identified attributes on future tree and stand yields; and, iii) the hierarchy of attributes and their severity leading to the identification of which trees, relative to their neighbouring trees, should be cut to improve a forest stand. Though attributes like types of defects and classes are usually well-defined, the classification itself remains based on qualitative appreciations. Consequently, two professional foresters 
could look at the same tree, agree on types of defects but fail to agree on the hierarchy of the types of defects and/or the severity of those defects. Therefore their tree selection results may diverge. The marteloscope is an appropriate setting for professional foresters working in a region to standardize interpretations of qualitative criteria, to set baselines and to agree upon the interpretation of observations of diverse kinds needed to make tree selection. The expected outcome is that, given a silvicultural objective (i.e., prescription), there would be less and less disagreement among professionals in the assessment of forest stands and in decision-making.

\section{Training aid for forestry schools}

Forest management is an exercise in decision-making, of which actual results can only be seen and assessed after many years or decades as forest growth is slow. Thus training the forestry workforce that makes those decisions is not to be approached lightly. In every country where there is a minimum of forest cover, forestry schools are essential parts of the education system. In such schools, curricula are designed to teach trainees how to make tree selection in forest stands to achieve various silvicultural objectives. Natural forest stands and particularly hardwood ones are very diverse and complex in composition, structure (horizontal as well as vertical) and state (i.e., vigor).

From the viewpoint of many forestry schools, a marteloscope's primary purpose is to serve as a teaching aid for demonstration and hands-on training of tree selection concepts (Junod 2010). Explanations of silvicultural concepts and how to apply them to the tree selection in a selective cut are covered in textbooks. However, one needs to acknowledge the limits of textbooks to effectively convey the inherent complexity of natural ecosystems like forests. Marteloscopes allow the transition between the textbook representation and the complexity of the real stand. At the same time, it offers the means to ensure that trainees have a common understanding of tree and stand attributes as well as the concepts that were presented in class.

Moreover, the ability to quickly run trainees' selection results into a growth-and-yield model or any other accompanying software allows students to envision the future stand and critically revisit their tree selection decisions. The marteloscope thereby enhances interactions between students and stimulates learning. In addition, the setting allows a trainee to try out various approaches/scenario of cuts, visualize and compare their results and draw lessons on decisionmaking in situations of conflicting approaches.

The Université de Moncton's forestry school has been using marteloscopes for three years in an attempt to improve the transition from knowledge of theoretical concepts into field competencies. The first benefit of bringing students into 1.2 ha permanent plots was the ability for teachers to quickly adjust the amount of data available to students and to ensure they can focus on the learning objectives. Maps of the location of trees allow students to analyse spatial distribution of various tree attributes as well as to appreciate the distribution of their selection. The scale of the plot allows students to plan for and appreciate the impacts of extraction trails. It also made the exercise of identifying rare elements of conservation value (large cavity trees, vernal pools) more realistic within the tree marking exercise. The 1.2 ha plot size, however, proved to be too small for silvicultural treatments that would be heterogeneous. Therefore, students planning a patch selection cut or hybrid selection cut would place a very limited number of patches within the plot. This tended to restrict their freedom to prescribe and test original treatments. In an exercise where trees are marked using flagging tape, students get a unique point of view closer to the reality of tree markers or loggers, compared to simply noting tree numbers on a piece of paper or on an electronic form. Access to a spreadsheet directly in the field provides quick feedback making it possible to validate and adjust decisions, as the decision process they followed originally is still fresh in their minds. As a result, it was felt that students handed in reports that reflected a more complete understanding of the strategy they were proposing and of the criteria they used to mark trees. Students could also discuss the level of success of their proposition relative to the given tree marking goals. To date, the use of marteloscopes as a training aid proved to be a great addition to bring students to an in-depth appreciation of the nuances of tree selection and helps them realize some of the challenges induced by heterogeneous stand conditions and maintaining stand quality for future generations. Marteloscopes allow for easily adding complexity to the tree marking exercise simply by forcing the students to consider extra constraints such as limitations induced by the choice of a harvesting system. Marteloscopes also proved very useful to illustrate new or uncommon silvicultural treatments such as continuous cover irregular shelterwood (Raymond et al. 2009) for which demonstration plots would otherwise not be readily available in a given region.

Finally, it is important to recognize that the permanent nature of the plots does not necessarily mean that harvesting is prohibited. In fact, harvesting a marteloscope following a consensus on tree selection can actually help complete the learning experience. In Switzerland, the Centre de compétence en sylviculture uses a network of marteloscopes on an approximately 10-year cycle where each marteloscope is used for tree selection exercises for a two to three-year period before being harvested. The growth rate of their forest allows that they are back in that marteloscope five-seven years later to begin again tree marking while being able to observe the actual response to past harvests (P. Junod, forest engineer, Centre de compétence en silviculture; pers. comm., 2014).

\section{Training aid for logging companies}

Logging companies employ a number of professionals of various experiences and backgrounds to do the actual task of logging forest stands. It follows that training is required to ensure that loggers can produce consistent and acceptable results. Marteloscopes offer settings where loggers can be trained to the same criteria for assessing a forest stand and making tree selection decisions. This is of particular importance for forest professionals without formal training, common in many parts of the world, especially for manual workers and machine operators. A simple tree marking exercise can quickly eliminate discrepancies in the interpretations of the prescribed treatment.

It is also important to recognize that, while many workers may not have the scientific or professional vocabulary necessary to describe every characteristic of a tree, they can often easily learn how to recognise visually the presence of 
important characteristics. Training in a marteloscope setting allows workers and professionals with different "languages" to agree on a common understanding of important tree selection criteria.

Training aid for continuous education of the forestry workforce Marteloscopes appear to be an ideal place for forestry professionals to gather and exchange experiences they acquire in their practice (Junod 2010). With marteloscopes installed in different types of forest ecosystems common to a region, a learning tour of forest professionals will give opportunities to those more acquainted with a particular type of stand to share their particular knowledge of that type with their peers. Such tours allow rich exchanges between professionals where similarities and differences among types of forest stand, objectives, scenarios, operations and outcomes will be discussedand-most importantly, expected outcomes of differences may be simulated on the spot.

In 2013 as part of a field day of the fall meeting of the Canadian Woodlands Forum, more than 100 forestry professionals (i.e., loggers, landowners, foresters, mill managers) exchanged ideas on the challenges of managing hardwood forests in northwestern New Brunswick before being asked to participate in a tree marking exercise to validate their perceptions (Lussier and Fontaine 2013). The activity proved to be a major trigger of passionate discussions. It also triggered many new ideas and prompted the launch of a new applied research project while convincing some logging companies to seriously consider increasing the training of their workforce (Lussier and Fontaine 2013). Most participants started the activity not expecting to learn anything new or to find benefits. After having performed the exercise and having had time to review the actual results of their selections, the participants had a very different perspective of the potential of marteloscopes for improving their understanding of each situation. In the weeks following the exercise, participants were contacted individually to obtain feedback, comments and suggestions on how to improve the activity. Overall, the marteloscope with its visualization complement turned an otherwise ordinary field visit into an interactive and truly educational exercise. From there, many participants indicated that being paired with another participant made them realise how different they actually interpreted the significance of various attributes and raised awareness of multiple interpretation possibilities.

At a larger scale, initiatives such as the Hammer project cited previously contribute to developing a common understanding and operational consistency over large networks of professionals and across borders for those forest ecosystems that are shared by more than one Country/Region (e.g., alpine continuum, shared by Austria, France, Germany, Italy, Slovenia and Switzerland).

\section{Marteloscopes for research}

Marteloscopes also offer a powerful platform upon which different research themes related to tree selection may be explored. Pommerening et al. (2015) outlined a number of research questions that have yet to be considered but for which the settings of a marteloscope are particularly adapted. Following are a few examples of recent and current research conducted to illustrate this.

\section{Human tree selection behavior}

The debate about the suitability tree selection by logger and harvester operators lacks solid data upon which to ground the various arguments. Bringing together more than 60 certified foresters, loggers and agronomists in two marteloscopes in Italy, Spinelli et al. (2016) were able to document the level of agreement in trees selected between the different professional figures. They were able to show that little agreement existed in trees selected for harvest between the three groups of professionals, but also that even more disagreements existed between individuals within groups of professionals. On the other hand, some agreement by all participants seemed to appear when looking at future crop trees selected. Pommerening et al. (2015) reported similar trends in the level of agreement from groups of forest professionals in marteloscope settings in the United Kingdom. Considering that individually, professionals pursuing the same silvicultural objectives and placed in the same forest stand are likely to come up with different tree selections on different occasions, these observations suggest that tree marking has more to do with human decision-making and behaviour than with natural/forest science. As such, tree marking in marteloscopes (a permanent setting) offers an insight in human factors that govern tree selection.

\section{Factors influencing the quality of tree selection}

In hardwood stands in eastern Canada, Brassard et al. (2003) looked into factors that would influence the ability to perform tree marking (i.e., its productivity and the quality of the tree selection for a given prescription). Their results suggested the influence of factors such as the level of experience of the tree marker; however, the experimental setup was not ideal to control other confounding factors, which limited their ability to analyse the results and reach significant conclusions. In response, Auger (2015), proposed an experimental design based on a set of five marteloscopes to determine the influence of various factors presumed to influence the "quality" of tree selection, namely: level of training, years of experience, mobility (to assess the impact of harvester operators constrained to make tree selection from their cabin compared to tree markers or loggers who can walk around trees), and time available to make the decision. The implementation of that design with five workers to test the protocol demonstrated that marteloscopes provide a well-adapted experimental environment very similar to actual work conditions while also permitting for the control of factors external to the design.

\section{Cost-benefit evaluation of different tree selection approaches}

Eastern North America has two contrasting tree selection approaches widely applied throughout the territory in similar stands with similar management objectives: i) trained loggers and harvester operators perform tree selection as they proceed harvesting the stand (common practice in New Brunswick and Nova Scotia); ii) certified tree markers select and mark trees to be harvested prior to loggers entering the stand to perform the harvest (common to Québec and Ontario). Structural changes of the past decades in the forest industry has drastically reduced profitability and the state of the forest imposes pressures to ensure that optimum choices are made to ensure the continuity of the current level of harvest as well as minimizing operation costs. Case studies to 
document cost differences between the two approaches were successfully performed in real harvesting contexts (Girard 2008b, Roy 2009, FPInnovations Division Feric 2010). However, quantifying differences in benefits (i.e., quality of tree selection) was limited, partly because of study complexity and a lack of suitable physical settings for the study. We suggest that marteloscopes could offer an adequate setup to perform such tests and allow for drawing conclusions driven by actual observations rather than the current debate on concepts and on theoretical benefits of either approach. Similarly, others in Europe suggest that marteloscopes are particularly suited to evaluate the consequences, such as the cost of application of marking trees for different objectives, for example for timber versus biodiversity characteristics (Pro Silva France 2003).

\section{Marteloscopes for extension and knowledge transfer}

As forests are an important part of the environment, most people have a relatively strong opinion about their management, even if they do not have background knowledge of forestry. In the face of such widespread "uninformed" opinions on their profession, professionals can use or adapt marteloscopes for knowledge transfer activities directed to a public with various levels of knowledge, experience or interest in forestry (Gineste 2010). As McKenney and Levine (2013) put it, "few people outside of the forestry profession have had the chance to get a hands-on experience of tending a forest (...). A session with the marteloscope will give non-professionals a feel for the complex choices and unique skill sets that are required to manage forests".

The importance of biodiversity and sustainable development has created both, a need for raising awareness of the general public, and touristic opportunities. Given the attributes of marteloscopes for transferring knowledge, it is not surprising to see one as a tourist attraction that serves the double purpose of retaining tourists in a region by providing a unique activity and provides a great opportunity to share knowledge on trees, forest and their management (Trossat 2009).

\section{Woodlot owners}

In rural forested regions, woodlot owners are often looking for advice from professionals with regard to the management of their lots. Marteloscopes are well adapted to conduct information sessions and workshops to educate woodlot owners. Unusual forestry concepts can be taught and different approaches/scenarios of management could be simulated with their results shown and the future forest derived from each scenario could be visualized by the woodlot owners. As the common expression goes, "seeing is believing". By allowing woodlot owners to test their own approach, marteloscopes can increase the odds that they will adopt better practices.

\section{Policy- and decision-makers}

Most often politicians enact laws that affect forest management and forestry professionals in their work without much knowledge of the forest and its complexity. In certain regions of Canada, local politicians at different levels of government and their representatives are regularly invited to take part in dedicated field tours. Marteloscopes could become part of such tours to help visualize the questions being discussed and the challenges of sustainable management. When time is limited, the interactive platform (i.e., the marteloscope software) can be used by itself to convey the expected consequences of different scenarios needing decision.

Interestingly, marteloscopes are also showing to be a relevant tool in shared forest governance schemes where the participation of a broad range of the population is called upon to play an active role in forest management (Quali Gouv 2012). With increased public participation in the forest management process, new needs for knowledge transfer are appearing; marteloscopes could likely play a prominent role.

\section{Youth}

Nowadays where extreme opinions tend to claim centre stage, outrageous claims made by news media about forest management and the forest industry are harmful to forest professionals. Marteloscopes can be a good tool for the education of students and help them contextualize the information that is brought to them by the sensationalist media. Tours with hands-on activities where the youth will implement management options and visualize the future forest deriving from their decisions will help them build their own informed opinions about the profession of forestry.

\section{Ongoing Developments}

A persisting challenge with forestry-related training is the distance that often needs to be travelled to reach the desired variety of forest settings. To improve on the trade-offs between classroom training and field exercises, different organizations are developing "virtual forests" and considering the potential of augmented reality in forestry. The idea is to offer realistic forest settings within a classroom context. As such, marteloscopes increasingly serve as the basis for such virtual forests. From the convenience of an office or classroom, one can "navigate" through a virtual representation of the stand, and sometimes even use an interface to select trees. The marteloscope database can easily be supplemented with data from various remote sensing technologies, such as terrestrial LIDAR, effectively increasing the possibilities of augmented reality. When performed on the basis of an actual marteloscope, participants can spend time performing exercises in the field, then pursue detailed analysis of their results and try to improve their performance using the virtual version of the marteloscope.

\section{Limits of Marteloscopes}

The examples above present the potential and benefits of marteloscopes. Just like everything else, they also have limitations, namely:

- Initial set-up of plot with the adaptation of a software can require extensive resources;

- Forest evolves with time hence particular characteristics are often ephemeral and require frequent update of data;

- There is not yet a common software or platform for sharing and analysing data of other marteloscopes;

- Data acquired in different marteloscopes may not follow a standard format or definition;

- It can be challenging to bring the participants, general public, politicians and decision-makers on site (Ginest 2010);

- Success of activities is highly dependent on the availability, competence and dynamism of the animator (Ginest 2010);

- Small scale limits effective consideration of certain silvicultural options; and, 
- Software usually requires constant updates and revisions both to follow technological changes and evolution in the data and exercises.

\section{Towards the Development of a Worldwide Network of Marteloscopes}

Marteloscopes are proving to be a useful tool to increase the effectiveness of knowledge transfer and training activities, in addition to being a powerful research platform for human tree selection behavior. Their ability to allow people to validate their personal perception of their tree selection performance against current knowledge and understanding, as well as against the performance of others, is a solid starting point for constructive discussions based on transparent factual data. In consequence, the last decade saw a transition from marteloscopes being set-up as individual and independent initiatives, to networks of sites with a more standardized protocol and software. We do not foresee any reasons why further expansion of networks of marteloscopes would stop. As the New England Forestry Foundation puts it in its spring 2013 newsletter, "marteloscopes can be expected to appear in a forest near you" (McKenney and Levine 2013). Likewise, the term is likely to increasingly become part of the forestry vocabulary.

\section{Acknowledgments}

We are grateful to Mr. Michel Huot for his comments and suggestions that allowed us to improve this article.

\section{References}

Ammann, P. and P. Junod. 2012. Installation d'un marteloscope, chronologie des opérations / Einrichten eines Marteloskops, zeitliche Abfolge der Arbeitsschritte. Fachstelle Waldbau (FWB) Centre de compétence en sylviculture (CCS). 4 p.

Arbogast, C., Jr. 1957. Marking guides for northern hardwoods under the selection system. USDA For. Serv. Lake States For. Exp. Stn. \# $56.21 \mathrm{p}$.

Auger, M. 2015. Proposition d'une méthodologie visant à mesurer leffet des facteurs susceptibles d'affecter la qualité des choix des tiges à récolter. Mémoire de fin détudes. Baccalauréat en sciences forestières, École de foresterie, Université de Moncton. Edmundston, Canada. 54 p.

Baar, F and B. Collard. 2007. Marteloscope du Beau Mousseau exercice de martelage en futaie irrégulière feuillue. Forêt Wallonne asbl, Namur, Belgique. Dans le cadre du projet Coopération pour un Renouveau Sylvicole (CooRenSy). 62 p.

Brassard, F., B. Boulet and G. Landry. 2003. Essai de martelage avec le guide d'interprétation des défauts indicateurs de carie des arbres: Projet d'amélioration des coupes de jardinages phase II. Ministère des Ressources naturelles, de la Faune et des Parcs du Québec. 42 p.

Bruciamacchie, M., J.-C. Pierrat and J. Tomasini. 2005. Modèles explicatif et marginal de la stratégie de martelage d'une parcelle irrégulière. Ann. For. Sci. 62 : 727-736. Doi : 10.1051/forest :2005070.

Burrus, R. and J.-M. Mourey. 2011. Initiatives et créativité des forestiers en matière de biodiversité. Revue Forestière Française 63(5): 509-525.

CCS. 2016. (Centre de compétence en sylviculture). Marteloscopes [online]. Available from http://www.waldbau-sylviculture.ch/ 94_martelo.php [accessed 09 June 2016].

Cimon-Morin, J., J.-C. Ruel, M. Darveau, J.-M. Lussier, P. Meek and V. Roy. 2010. Essais de jardinage sans martelage dans des peuplements irréguliers de sapin baumier et dépinette noire. Forest. Chron. 86(4): 498-510.
Franklin, J.F., D.R. Berg, D.A. Thornburgh and J.C. Tappeiner. 1997. Alternative silvicultural approaches to timber harvesting: Variable retention harvest systems. In Creating a Forest for the $21^{\text {st }}$ Century: The Science of Ecosystem Management. (eds. K.A. and J.F. Franklin), Island Press, Washington, D.C. 111p.

FPInnovations Division Feric, 2010. Comparaison de trois traitements sylvicoles en forêt feuillue au secteur Kay-Nord à l'hiver 2010. FPInnovations. Pointe-Claire, QC. Rapport de contrat RC-551. 12 p. Génot, J.-C. 2009. Des "marteloscopes" pour former et analyser. SycoParc, no 38, numéro spécial: lettre d'information du Syndicat de coopération pour notre parc naturel régional (Vosges du Nord). Available from http://www.parc-vosges-nord.fr/ [accessed 14 June 2016].

Gineste, M. 2010. Martéloscope : développement d'une interface pédagogique pour un public non spécialisé. Mémoire de fin d'études. AgroParisTech ENGREF. Nancy, France. 94 p.

Girard, P. 2008a. Développement d'une méthode de récolte en forêt feuillue jardinée avec choix de tiges par l'opérateur, FPInnovations (FERIC). $12 \mathrm{p}$.

Girard, P. 2008b. Observation d'une opération de coupe partielle mécanisée au Nouveau-Brunswick, FPInnovations, division Feric, Pointe-Claire, QC. Canada. 6 p.

Integrate+. 2015. Marteloscopes: Description of parameters and assessment procedures. Version 0.2. European Forest Institute, Regional Office EFICENT, Wonnhaldestr. 4, 79100, Freiburg, Germany. 16 p. Available at http://www.integrateplus.org/ [accessed 6 June 2016].

Integrate+. 2016. Map of Marteloscopes [online]. Available from: http://www.integrateplus.org/Demo-Sites/What-is-a-Marteloscope/table.html [accessed 9 June 2016].

Junod, P., 2010. Marteloscope. Forêt communale de Cortaillod, division 4 . Futaie irrégulière finement mélangée. Forêt - bois neuchatelois. Arrondissement forestier de Boudry, Cortaillod, Switzerland. 13 p. Available from: http:// http://www.waldbau-sylviculture.ch/ mar/CD04_f.pdf [accessed 10 June 2016].

Life+ PProSpoT. 2014. The afterlife communication plan. Policy and protection of sporadic tree species in Tuscany forest. Report LIFE09 ENV/IT/00087. 12 p. Available from: www.pprospot.it [accessed 9 June 2016].

Lussier, J.M. and P. Fontaine. 2013. L'IFC/CIF SEEK - Première activité de la COMmunauté de Pratique sur la Sylviculture inéquienne. Forest. Chron. 89 (6): 732-733.

Maistrelli, F. 2014. I « Martelloscopi » in Alto Adige : 10 anni d'esperienza pratica ed evoluzione futura. Proceedings of the second international congress of silviculture. Florence, Italy. November $26^{\text {th }}$ - $29^{\text {th }}$ 2014. pp. 859-863. Accessible at: http://dx.doi.org/10.4129/ 2cis-fm-mar [accessed on 1 June 2016].

Meadows, J. S. and D.A. Skojac, Jr. 2008. A new tree classification system for southern hardwoods. South. J. Appl. For. 32(2): 69-79

MFFPQ. 2016. Martelodromes d’exercice. Ministère des forêts, de la faune et des Parcs du Québec. [online]. Available from: https://www.mffp.gouv.qc.ca/forets/entreprises/entreprises-martelage-exercice.jsp [accessed 9 June 2016].

McKenney, D. and L. Levine. 2013. The marteloscope - Coming to a forest near you! An innovative tool in the practice of sustainable forest management. New England Forestry Foundation - Conserving forests for future generations. Into the woods - quarterly newsletter. Spring 2013. New England Forestry Foundation, 32 Foster Street, Littleton, MA 01460. Available from www.newenglandforestry.org [accessed 14 June 2016].

OMNR. 2004. (Ontario Ministry of Natural Resources). Ontario Tree Marking Guide, Version 1.1. OMNR. Queen's Printer for Ontario. Toronto. 252 p.

Pommerening, A. and S.T. Murphy, 2004. A review of the history, definitions and methods of continuous cover forestry with special attention to afforestation and restocking. Forest. 77(1): 27-44. doi: 10.1093/forestry/77.1.27 
Pommerening, A., L. Vitkova, X. Zhao and C. P. Ramos. 2015. Towards understanding human tree selection behaviour. Forest Facts; results from the Swedish University of Agricultural Sciences. Nr 9.6 p. ISSN:1400-7789

Poore, A. 2011. The marteloscope - a training aid for continuous cover forest management. Woodland Heritage 2011, 28-29. Available from: http://www.woodlandheritage.org [accesses 9 June 2016] Pro Silva. 2012. Pro Silva principles. 67 p. Available from: http://www.prosilvaeurope.org/ [accessed 8 June 2016].

Pro Silva France. 1995. Raisons possibles pour le maintien et l'enlèvement d'un arbre lors du martelage. Available from: http://www.prosilva.fr [accessed 9 June 2016].

Pro Silva France. 2003. Méthodologie dévaluation du coût d'un martelage favorable à certains éléments de la biodiversité. Cas de la forêt de Zittersheim. Pro Silva France and the Syndicat de Coopération pour le parc naturel régional des Vosges du nord. 25 p. Available from: http://prosilva.fr [accessed 9 June 2016].

Pukkala, T. and K. von Gadow (eds.). 2012. Continuous cover forestry. Managing forest ecosystems Vol. 23, Springer Netherlands. 296 p. DOI 10.1007/978-94-007-2202-6

Quali Gouv. 2012. Le martéloscope, un outil de sensibilisation pratique et efficace. Éclairage thématique no 6.8 p. Available from: http://www.aifm.org/sites/default/files/ET6_opt.pdf [accessed 14 June 2016].

Raymond, P., S. Bédard, V. Roy, C. Larouche and S. Tremblay. 2009. The irregular shelterwood system: review, classification, and potential application to forests affected by partial disturbances. J. Forest. 107(8): 405-413.

Roy, V. 2009. Résultats préliminaires: Jardinage sans martelage. FPInnovations division Feric. Pointe Claire, Québec. Available from: http://hardwoodinitiative.fpinnovations.ca/publicationsfr/ [accessed 1 June 2016].
Ruel, J.C., V. Roy, J.-M. Lussier, D. Pothier, P. Meek and D. Fortin. 2007. Mise au point d'une sylviculture adaptée à la forêt boréale irrégulière. Forest. Chron. 83(3): 367-374.

Schuck, A. and D. Kraus, 2015. Learning lessons from virtual tools - Integrating biodiversity into forest Management. European Forest Institute, Newsletter, pp. 18-19. Available from http://www.integrateplus.org/uploads/images/Mediacenter/EFI_News_Nov_2015_I ntegrate_Article.pdf [accessed 6 June 2016].

Schuck, A., D. Kraus and F. Krumm. 2016. Integrate+ Marteloscopes - calibrating silvicultural decision-making. Integrate+ Technical Paper. $12 \mathrm{p}$. Available at http://www.integrateplus.org/ [accessed 6 June 2016].

Soucy, M. 2014. Protocole d'installation des marteloscopes. Faculté de foresterie, Université de Moncton, Edmundston, Canada. 17 p. Available from: http://www.umoncton.ca/umce-foresterie/node/160 [accessed 6 June 2016].

Spinelli, R., N. Magagnotti, L. Pari, and M. Soucy. 2016. Comparing tree selection as performed by different professional figures. Forest Science. Vol. 62: 213-219

Torreggiani, L. S. Bruschini and P. Mori. 2012. Martelloscopi PProSpoT; Virtual tree marking areas for professional training. Sherwood $n^{\circ} 186.4 \mathrm{p}$.

Trossat, J. 2009. Martelloscope, des émotions entre science et nature. Tourisme Auvergne Rhône-Alpes. [online]. Available from http://pro.rhonealpes-tourisme.com/article/martelloscope-desemotions-entre-science-et-nature [accessed 14 June 2016].

Vítková, L., Á. Ní Dhubháin and A. Pommerening. 2016. Agreement in Tree Marking: What Is the Uncertainty of Human Tree Selection in Selective Forest Management? For. Sci. 62 (pre-print). doi: http://dx.doi.org/10.5849/forsci.15-133 